\title{
Effects of pomegranate extracts on cartilage, bone and mesenchymal cells of mouse fetuses
}

\author{
Malihezaman Monsefi ${ }^{1 *}$, Fatemeh Parvin ${ }^{1}$ and Tahereh Talaei-Khozani ${ }^{2}$ \\ ${ }^{1}$ Department of Biology, College of Sciences, Shiraz University, Shiraz, Iran \\ ${ }^{2}$ Department of Anatomy, School of Medicine, Shiraz University of Medical Sciences, Shiraz, Iran
}

(Received 23 July 2010 - Revised 13 May 2011 - Accepted 13 May 2011 - First published online 25 July 2011)

\begin{abstract}
Pomegranate is a rich source of polyphenols, which are believed to be responsible for the oestrogenic activities of extracts of this fruit in mice. One of these potential activities is the prevention of bone loss. The objectives of the present study were to determine the effects of pomegranate extract on chondrogenesis and osteogenesis in mouse embryos in vivo and limb bud cultures in vitro. A total of fifty pregnant $\mathrm{Balb} / \mathrm{c}$ mice were given vehicle, pomegranate juice extract (PJE), pomegranate husk extract (PHE) or a mixture of husk and juice extract (PME). Their embryos were stained with alizarin red $\mathrm{S}$ and alcian blue, and the length of the femur, tibia and their ossification zones were measured on day 19 of gestation. Bone Ca content in pregnant mice was also measured. Mice treated with PJE showed an increase in bone Ca content. Dietary supplementation with all extracts significantly increased embryo femur length and osteogenesis index. Mesenchymal cells from fetal limb buds were cultured and exposed to 10, 100, 1000 and $10000 \mu \mathrm{g} / \mathrm{ml}$ of PJE, PHE or PME. The number of viable cells was greater in cultures exposed to the extracts than in control cultures. The number of cartilage nodules and their diameters were greater in extract-treated cell cultures, a finding which reflected increased cell proliferation and differentiation rates. In conclusion, the findings of the present study suggest that pomegranate is able to enhance bone formation.
\end{abstract}

Key words: Bone: Calcium content: Chondrogenesis: Fetuses: Mesenchymal cells: Osteogenesis: Pomegranates

Pomegranate (Punica granatum L., a member of the Punicaceae family) is native to Iran and the Himalayan region of India, and is one of the oldest known fruit species ${ }^{(1)}$. Pomegranate fruits contain numerous arils ranging in colour from white to deep red. Each aril consists of a dense white portion or husk in the centre, surrounded by tart red juice. The principal constituents of pomegranate juice are anthocyanins, ellagic acid, gallic acid and numerous minerals. Pomegranate seed oil contains punicic acid, ellagic acid, steroidal oestrogen, oestrone and non-steroidal phytooestrogens $^{(2)}$ including comesten, coumoestrol, and isoflavones, genistein and daidzein ${ }^{(3)}$. Phyto-oestrogens such as coumoestrol enhance osteoblast proliferation in neonatal and adult mice ${ }^{(4)}$. Oestrogens play an important role in the growth and maintenance of numerous tissues, and act through intracellular oestrogen receptors $(\mathrm{ER})^{(5)}$. ER $\alpha$ and ER $\beta$ receptors are expressed in bone ${ }^{(6,7)}$, and the expression of ER increases substantially during bone mineralisation ${ }^{(6)}$. The phyto-oestrogen genistein shows higher affinity for ER $\beta$ than for $\mathrm{ER} \alpha^{(8)}$, a finding which suggests that dietary phytooestrogens can play a role in bone remodelling ${ }^{(9)}$. In this connection, Mardon et $a l^{(10)}$ demonstrated an increase in bone mineral density (BMD) in rat fetuses exposed to isoflavones.

The administration of pomegranate extract to ovariectomised mice normalised BMD and increased bone volume and trabecular number. It was also clinically effective in improving depressive state and reducing bone loss in women with the menopausal syndrome ${ }^{(11)}$. Pomegranate extract prevented chondrocyte damage and changes in the matrix proteoglycans of the tibiofemural joints in a mouse model of osteoarthritis induction ${ }^{(12)}$.

Despite these earlier findings, we found no published studies designed to investigate the effects of pomegranate fruit on bone histogenesis under normal conditions, particularly during the embryonic period. We hypothesised that pomegranate can improve chondrogenesis and osteogenesis. Because the mother's diet affects the fetus, the present study was designed to investigate the effects of feeding with pomegranate extracts on the chondrogenic and osteogenic potential of fetal limb bud mesenchymal cells in an in vitro and in vivo mouse embryo model.

Abbreviations: BMD, bone mineral density; BSAI-B4, Bandeiraea simplicifolia agglutinin; CRL, crown-rump length; ER, oestrogen receptor; PHE, pomegranate husk extract; PJE, pomegranate juice extract; PME, mixture of pomegranate husk and juice extract.

*Corresponding author: M. Monsefi, fax +98 7112280916 , email monsefi@susc.ac.ir 


\section{Materials and methods}

\section{Extract preparation}

P. granatum L. cultivar Rabbab fruits were collected from the town of Eig located at $54^{\circ}, 14^{\prime}, 26.39^{\prime \prime}$ E, $29^{\circ}, 00^{\prime}, 46.27^{\prime \prime} \mathrm{N}$ (Estahban, Fars Province, Southern Iran) and the species was verified by a pomologist at the Horticultural Science Department, School of Agriculture, Shiraz University, Shiraz, Iran. The pomegranates were peeled and the arils were separated. The husks (seeds) and juice were separated in a mixer. Pomegranate juice $(400 \mathrm{ml})$ was obtained from $500 \mathrm{~g}$ arils, and was then condensed to $100 \mathrm{ml}$ at $60^{\circ} \mathrm{C}$ using a water-bath and a dessicator. The yield (w/w) of the juice extract was $16 \%$ $(\mathrm{g} / \mathrm{g})$. The husk extract was obtained with the percolation method. Husks were dried and powdered in a dessicator for $24 \mathrm{~h}$, and $1.60 \mathrm{~g}$ husk extract was obtained from $30 \mathrm{~g}$ powdered husks. The final yield was $5 \cdot 3 \%(\mathrm{~g} / \mathrm{g})$ powdered extract.

\section{In vivo study}

A total of fifty female Balb/c mice weighing 30-40g were obtained from the animal house of Razi Institute in Shiraz. The animals were adapted to the laboratory conditions for 2 weeks before the beginning of the experiments. The animals were housed under controlled temperature $\left(22-24^{\circ} \mathrm{C}\right)$ and light conditions with a $12 \mathrm{~h}$ light $-12 \mathrm{~h}$ dark period. All mice had free access to food and tap water. The animal experiments were approved by the Institutional Animal Ethics and Health Committee of the Biology Department of Shiraz University, and were performed according to the principles of the care and use of laboratory animals established by the National Institute of Health. Female mice were caged with males and insemination was verified the following morning by checking for the presence of a copulation plug in the vagina. The day the vaginal plug was observed was considered day 0 of pregnancy. The mice were weighed on days 5, 8, 12 and 15 of gestation.

Pregnant mice were divided into one control and three experimental groups ( $n$ 10). In the three experimental groups, pregnant mice were given a daily oral dietary supplement containing pomegranate juice extract (PJE, $3.3 \mathrm{ml} / \mathrm{kg}$ ), pomegranate husk extract (PHE, $1.0 \mathrm{~g} / \mathrm{kg}$ ) or a mixture of equal parts of husk and juice extracts (PME) between days 8 and 18 of gestation, the period when the embryonic limb buds are developing. The control group received only equal volumes of distilled water under similar conditions. The different doses of extracts were suspended in $0.2 \mathrm{ml}$ distilled water

On day 19, the embryos in each group were weighed and their crown-rump lengths (CRL) were measured. The embryos were then fixed with formaldehyde. All embryos were examined for congenital malformations by stereomicroscopy.

\section{Osteogenesis index measurement}

A total of 120 fetuses were fixed in $95 \%$ ethanol, and were skinned and eviscerated. They were defatted in acetone for $2 \mathrm{~d}$ and were stained with a mixture of alcian blue (Merck, Darmstadt, Germany) and alizarin red S (Riedel-de Haen,
Seelze, Germany). The fetuses were cleared in a series of decreasing concentrations of $\mathrm{KOH}$ in glycerine and then kept in glycerine. The cartilaginous skeleton was stained blue, and the ossified skeleton was stained red. Total femur and tibia length and the length of their ossified zones were measured under a stereomicroscope equipped with a ruled eyepiece (Zeiss, Mc-80; Jena, Germany). The osteogenesis index was calculated by dividing the ossified length by the total length of each bone (Fig. 2)

\section{Histological study}

A total of sixty-two fetuses were fixed in $10 \%$ buffered formalin and embedded in paraffin ${ }^{(13)}$. Then, $5 \mu \mathrm{m}$-thick longitudinal sections were prepared and stained with haematoxylin-eosin, and then examined under a light microscope to search for the evidence of pathological changes.

\section{Lectin histochemistry}

Deparaffinised and dehydrated sections were incubated in PBS containing $0 \cdot 1 \mathrm{~mm}-\mathrm{CaCl}_{2}, \mathrm{MgCl}_{2}$ and $\mathrm{MnCl}_{2}$. The endogenous peroxidase was blocked by incubating the sections in $1 \% \mathrm{H}_{2} \mathrm{O}_{2}$ in methanol for $10-15 \mathrm{~min}$. The specimens were then incubated with peroxidase-conjugated lectins (Sigma, St Louis, MO, USA) for $2 \mathrm{~h}$ at room temperature. The lectins of Ulex europeaeus agglutinin, Bandeiraea simplicifolia agglutinin (BSAI-B4) and concanavalin A, which bind to $\alpha$-L-fucose, galactose and $\alpha$-D-glucose, respectively, were used at a final concentration of $10 \mu \mathrm{g} / \mathrm{ml}$. After washing, the binding sites were visualised by incubating the sections in $0.03 \%$ diaminobenzidine containing $200 \mu \mathrm{H}_{2} \mathrm{O}_{2}$ in PBS for $10 \mathrm{~min}$. Then, the sections were counterstained with alcian blue (0.5\%). Photographs were taken with a digital camera. The intensity of the reaction to each lectin was assessed with Image-Java software (http://mac.softpedia.com/get/ Graphics/ImageJ.shtml).

\section{Calcium content measurement}

The femurs of pregnant mice were allowed to dry for $24 \mathrm{~h}$ at $56^{\circ} \mathrm{C}$. The air-dried bones were then ashed at $520^{\circ} \mathrm{C}$ for $20 \mathrm{~h}$ in an oven (Model 10500, Thermolyne, Dubuque, IA, USA). The bone was then powdered, and $0.03 \mathrm{~g}$ of the powder were dissolved in $250 \mu \mathrm{l} \mathrm{HCl}$; this solution was then diluted with $31 \mathrm{ml}$ distilled water. Standard solutions were prepared to contain $0.2 \mathrm{~g} \mathrm{CaCl}_{2}$ in $2 \% \mathrm{HCl}$ (density 720 parts per million). Stock solutions were diluted to 0.03 parts per million. Ca content was measured with a flame photometer (Model 8515, Jenway, Stone, Staffs, UK). The linear fit equation was calculated with Microsoft Excel (Microsoft Corporation, Redmond, WA, USA) as $y=0.0134 x+0.0221$, where $y$ is the bone $\mathrm{Ca}$ content and $x$ is the Ca content of the standard solution.

\section{Limb bud assay}

On day 12 of gestation, the fetuses were removed, the extraembryonic membranes were separated, and then the limb 
buds were cut away and collected in PBS containing penicillin/ streptomycin. The ectoderm was separated from underlying mesenchymal tissue by incubation in $0.8 \mathrm{U} / \mathrm{ml}$ dispase (Sigma) for $1.5 \mathrm{~h}$ at $37^{\circ} \mathrm{C}$. Mesenchymal cells were dissociated in $0 \cdot 1 \%$ trypsin (Sigma) for $20 \mathrm{~min}$ at $37^{\circ} \mathrm{C}$. Cell viability was assessed by trypan blue exlusion. The number of viable cells was adjusted to $2.5 \times 10^{7}$. High-density micromass culture was performed by placing $10 \mu \mathrm{l}$ of the cell suspension in the centre of each well of a twenty-four-well plate followed by incubation for $1.5 \mathrm{~h}$ at $37^{\circ} \mathrm{C}$. Each control well was then flooded with $0.5 \mathrm{ml}$ Dulbecco's modified Eagle medium/Nutrient Mixture F-12 (Sigma) containing 10\% fetal calf serum, 1\% L-glutamine, and $1 \%$ penicillin-streptomycin. PJE, PHE and PME were added to the culture media at concentrations of $10,100,1000$ and $10000 \mu \mathrm{g} / \mathrm{ml}$. Osmolality of the extractcontaining media was adjusted to 300-320 mOsm with an osmometer (model 030; Gonotec GmbH, Rinteln, Germany). The medium was replaced every day. All cells were incubated at $37^{\circ} \mathrm{C}$ with $5 \% \mathrm{CO}_{2}$ for 9 or $14 \mathrm{~d}^{(14)}$. Cell viability was assessed by neutral red $(0.05 \%)$ for $2 \mathrm{~h}$ at $37^{\circ} \mathrm{C}$, after which the cells were fixed in formal $\mathrm{Ca}$ for $1 \mathrm{~min}$ at room temperature and washed for $2 \mathrm{~min}$ in saline. Subsequently, $1 \mathrm{ml}$ alcohol acid was added and the mixture was incubated for $2 \mathrm{~h}$ at room temperature. The optic density of the eluted neutral red in alcohol acid was measured at a wavelength of $540 \mathrm{~nm}$ in a spectrophotometer (Shimadzu UV-120-01, Kyoto, Japan).

The cells were then rinsed in saline, fixed in Kahle's fixative for $20 \mathrm{~min}$ and stained with alcian blue (1\% in 3\% acetic acid) overnight. Chondrogenesis activity was assayed by counting the number of nodules and measuring their diameters. The intensity of the reaction to alcian blue indicated the amount of proteoglycan secreted by newly differentiated chondrocytes.

A similar method was used to quantify Ca content of the matrix by $1 \%$ alizarin red S staining in cells cultured for 9 or $14 \mathrm{~d}$. Ca content was also assessed by the Von Kossa staining method. The cells were washed with PBS, fixed in $10 \%$ formalin for $2 \mathrm{~h}$, and then stained with $2.5 \%$ aqueous silver nitrate for $30 \mathrm{~min}$. The cells were then rinsed and air-dried. The number and diameter of osteogenic areas were measured with stereological software designed $a d$ boc at our laboratory after calibration with an ocular micrometer.

\section{Statistical analysis}

The results are presented as means and standard deviations. Data were analysed by ANOVA. Tukey's, Scheffé's and the least significant difference method as post hoc tests were also performed. A $P$ value $<0.05$ was accepted as a statistically significant difference.

\section{Results}

\section{Effects of the extracts on pregnant female mice}

The body weight of pregnant mice was not affected by feeding with the pomegranate extracts. However, all extracts increased bone $\mathrm{Ca}$ content in pregnant mice (Table 1).

\section{Effects of the extracts on fetuses in vivo}

Weight and CRL were significantly smaller in the fetuses of PME-treated mice. Treatment with PJE and PHE did not significantly influence these indices compared with the control group. The effects of PJE and PHE on CRL and weight were smaller than in the PME group, therefore the weight and CRL of fetuses from these groups were significantly higher than in fetuses from the PME group (Table 1 and Fig. 1). Fetuses from pregnant mice fed with a diet containing pomegranate extract did not show any craniofacial abnormalities or limb defects, as indicated by gross observations.

The alcian blue/alizarin red S staining technique showed that total femur length was significantly longer in the fetuses of PJE-treated mice, whereas tibia length was not significantly different compared with the control group. However, the osteogenesis index in the tibia and femur was significantly increased in PJE-, PHE- and PME-treated fetuses compared with the control group. In the femur, the highest ossification index was observed in the PJE-treated group, and the difference was significant compared with the PME-treated group. In the tibia, the ossification index in fetuses from the PHE group was larger than in PME-treated mice (Table 2 and Fig. 2). These data indicated that the ossified zones of the limb bones were longer in extract-treated fetuses compared with the controls.

Table 1. Effects of pomegranate extracts on embryo weight and crown-rump length, number of fetuses and bone calcium content in pregnant mice (Mean values and standard deviations)

\begin{tabular}{|c|c|c|c|c|c|c|c|c|}
\hline \multirow[b]{2}{*}{ Groups } & \multicolumn{2}{|c|}{$\begin{array}{l}\text { Crown-rump } \\
\text { length }(\mathrm{cm})\end{array}$} & \multicolumn{2}{|c|}{ Weight (g) } & \multicolumn{2}{|c|}{$\begin{array}{l}\text { Number of } \\
\text { fetuses }\end{array}$} & \multicolumn{2}{|c|}{$\begin{array}{c}\text { Bone Ca } \\
\text { content } \\
\text { ( } \mu \mathrm{g} / \mathrm{g} \text { dry weight })\end{array}$} \\
\hline & Mean & SD & Mean & $\mathrm{SD}$ & Mean & SD & Mean & SD \\
\hline CON & 2.33 & 0.16 & 1.15 & 0.18 & 9.00 & 2.45 & 26.90 & 0.98 \\
\hline PJE & $2 \cdot 30^{\mathrm{a}}$ & 0.18 & $1 \cdot 16^{\mathrm{c}}$ & 0.21 & 7.80 & 3.19 & $28 \cdot 34^{\star}$ & 0.37 \\
\hline PHE & $2 \cdot 31^{\mathrm{b}}$ & 0.19 & $1 \cdot 14^{d}$ & 0.18 & 8.70 & $2 \cdot 21$ & 27.81 & 0.60 \\
\hline PME & $2 \cdot 20^{* a, b}$ & 0.11 & $1.00^{\star c, d}$ & 0.08 & 9.60 & 1.52 & 27.64 & 0.33 \\
\hline
\end{tabular}

CON, control; PJE, pomegranate juice extract; PHE, pomegranate husk extract; PME, mixture of pomegranate husk and juice extract.

a,b,c,d Mean values with unlike superscript letters were significantly different $(P<0.05)$.

${ }^{\star}$ Mean values were significantly different from those of the control group $(P<0.05)$. 


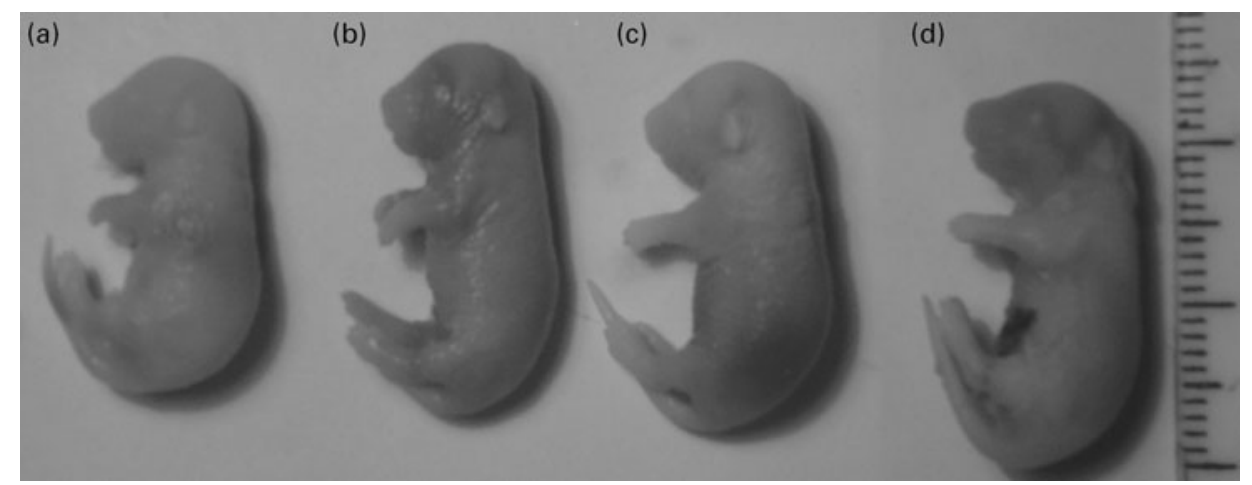

Fig. 1. Effects of pomegranate extract on the crown-rump length of mouse fetuses on day 18 of gestation. (a) Pomegranate mix extract-treated mice, (b) pomegranate juice extract-treated mice, (c) pomegranate husk extract-treated mice and (d) control mice.

Light microscopic observations revealed no pathological changes such as necrosis, abnormal cells or congestion in longitudinal sections of fetuses (Fig. 3). The liver and kidneys were normal in both fetuses and their mothers.

Daily dietary supplementation with PJE changed the proteoglycan content of the fetal cartilage matrix. In the vertebral column, chondrocytes and the extracellular matrix of the cartilage reacted more intensely to BSAI-B4 in PJE-treated fetuses compared with control fetuses. There were no significant differences in the intensity of the reactions to $U$. europeaeus agglutinin and concanavalin $\mathrm{A}$ in the cartilage or bone after extract treatment. However, both concanavalin A and BSAI-B4 showed stronger reactions in the PHE-treated group compared with the PME-treated group (Table 2 and Fig. 4).

\section{In vitro study}

Cell viability was first assessed after $9 \mathrm{~d}$ of culture with each extract. All three extracts at a concentration of $10000 \mathrm{mg} / \mathrm{ml}$ were toxic, and cell viability decreased significantly. Cell viability in cultures exposed to $100 \mu \mathrm{g} / \mathrm{ml}$ of PJE was significantly higher than in the other two groups. After $14 \mathrm{~d}$, cell viability decreased significantly in the presence of 10,100 and $1000 \mu \mathrm{g} / \mathrm{ml}$ of PJE and PME in comparison with control cultures (Table 3 ).

After $9 \mathrm{~d}$ of incubation, the diameters of the cartilage nodules increased significantly in the presence of $1000 \mu \mathrm{g} / \mathrm{ml}$
PHE, 100 and $1000 \mu \mathrm{g} / \mathrm{ml}$ PJE and $10 \mu \mathrm{g} / \mathrm{ml}$ PME. Moreover, cells treated with PHE at $1000 \mu \mathrm{g} / \mathrm{ml}$ formed more nodules than control cultures. Between-group statistical analysis revealed significant differences in mean nodule diameter between cultures exposed to different doses of the various extracts (Table 3)

After $14 \mathrm{~d}$ of culture with each extract, the mesenchymal cells formed ossifying areas with significantly larger diameters in the presence of the extracts compared with control cultures. However, lower doses of the extract decreased the number of ossified areas (Table 3 and Fig. 5). In other words, the number of cells that differentiated into osteoblasts was lower than in control cultures, although the differentiated cells precipitated more in the extracellular matrix. Statistical analysis showed that lower doses of each extract led to larger reductions in the number of nodules on days 9 and 14 of cell culture, especially in groups PHE and PME, compared with cultures exposed to the highest doses (Table 3). However, after $9 \mathrm{~d}$ of culture, the highest dose of each extract increased nodular diameter significantly more than the lower doses did (Table 3).

\section{Discussion}

PME fed to pregnant mice reduced the weights and CRL of their fetuses. In the PHE and PJE groups, pregnant mice gained less weight than those in the control group.

Table 2. Effects of pomegranate extracts on the total length of the femur and tibia, cartilagenous and ossified parts of the femur and tibia, ossification indices and lectin reaction intensity

(Mean values and standard deviations)

\begin{tabular}{|c|c|c|c|c|c|c|c|c|c|c|c|c|c|c|}
\hline \multirow[b]{2}{*}{ Groups } & \multicolumn{2}{|c|}{$\begin{array}{l}\text { Femur length } \\
(\mathrm{mm})\end{array}$} & \multicolumn{2}{|c|}{$\begin{array}{l}\text { Tibia length } \\
\quad(\mathrm{mm})\end{array}$} & \multicolumn{2}{|c|}{$\begin{array}{c}\text { Femur } \\
\text { osteogenesis } \\
\text { index }\end{array}$} & \multicolumn{2}{|c|}{$\begin{array}{c}\text { Tibia } \\
\text { osteogenesis } \\
\text { index }\end{array}$} & \multicolumn{2}{|c|}{$\begin{array}{l}\text { BSA1-B4 } \\
\text { (pixels) }\end{array}$} & \multicolumn{2}{|c|}{$\begin{array}{c}\text { ConA } \\
\text { (pixels) }\end{array}$} & \multicolumn{2}{|c|}{$\begin{array}{l}\text { UEA } \\
\text { (pixels) }\end{array}$} \\
\hline & Mean & SD & Mean & SD & Mean & SD & Mean & SD & Mean & SD & Mean & SD & Mean & SD \\
\hline CON & 1.74 & 0.22 & $2 \cdot 19$ & 0.24 & 0.58 & 0.07 & 0.62 & 0.06 & 111.38 & 4.92 & $105 \cdot 10$ & 8.08 & $109 \cdot 42$ & 14.99 \\
\hline PJE & $1.99^{*}$ & 0.25 & $2 \cdot 34$ & 0.24 & $0.65^{\star a}$ & 0.06 & $0.70^{\star}$ & 0.06 & $145 \cdot 44^{\star}$ & 13.5 & 99.05 & $15 \cdot 14$ & 114.66 & 22.52 \\
\hline PHE & 1.87 & 0.28 & 2.34 & 0.28 & $0.64^{*}$ & 0.04 & $0.70^{* \mathrm{~b}}$ & 0.05 & $139 \cdot 01^{\star c}$ & 6.43 & $132 \cdot 04^{d}$ & 13.52 & 129.99 & 12.56 \\
\hline PME & 1.84 & 0.21 & $2 \cdot 19$ & 0.20 & $0 \cdot 61^{* a}$ & 0.06 & $0.65^{\star b}$ & 0.05 & $124 \cdot 20^{C}$ & $10 \cdot 74$ & $92 \cdot 91^{d}$ & 19.95 & 120.69 & 16.95 \\
\hline
\end{tabular}

BSA1-B4, Bandeiraea simplicifolia agglutinin; ConA, concanavalin A; UEA, Ulex europeaeus agglutinin; CON, control; PJE, pomegranate juice extract; PHE, pomegranate husk extract; PME, mixture of pomegranate husk and juice extract.

a,b,c,d Mean values with unlike superscript letters were significantly different $(P<0.05)$.

* Mean values were significantly different from those of the control group $(P<0.05)$. 

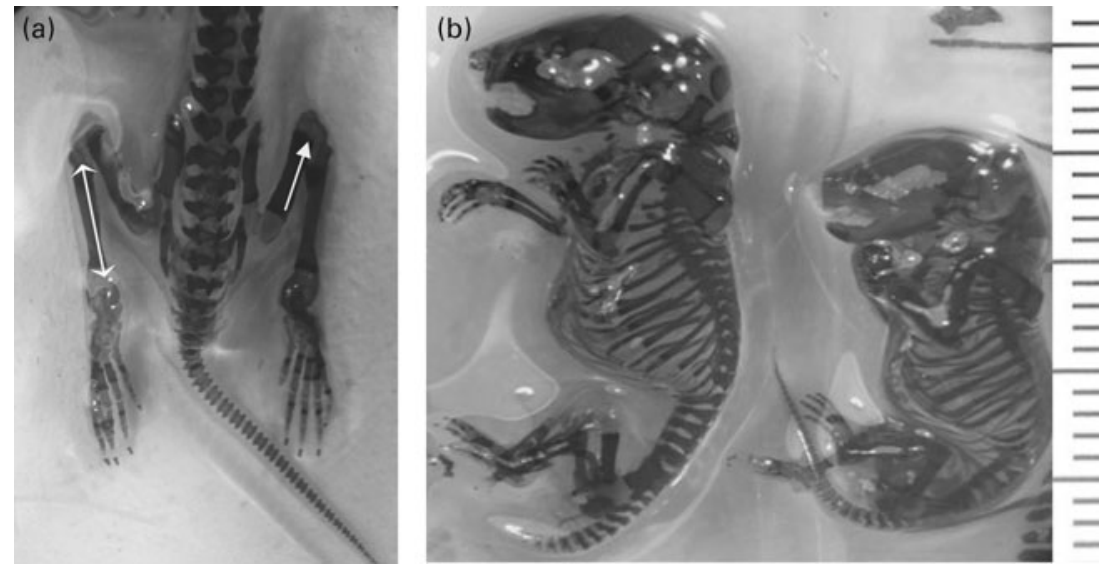

Fig. 2. Mouse embryos stained with alizarin red $\mathrm{S}$ and alcian blue. The cartilaginous and bony parts of the skeleton stained blue and red, respectively. (a) The effects of pomegranate extract on femur $(\rightarrow)$ and tibia $(\leftrightarrow)$ length are shown. (b) The ossification index was longer in mice treated with pomegranate juice extract than in control mice.

The smaller fetuses may have been responsible for the lower weight gain in these two groups. Fetal weight and CRL are influenced by various internal and external factors. A reduction in blood cholesterol and glucose has been reported after treatment with pomegranate juice or pomegranate seed oil ${ }^{(15,16)}$. Punicic acid found in pomegranate seed oil led to a reduction in body fat mass, body mass and blood cholesterol ${ }^{(17)}$. Other studies ${ }^{(18)}$ have documented the anti-obesity and hypolipidaemic effects of some flavonoids. Phyto-oestrogens such as genistein have been shown to decrease adipose deposition ${ }^{(19)}$. These components of the pomegranate extracts that we tested probably contributed to the lower weight gain in pregnant mice and their fetuses.

We found no morphological abnormalities such as craniofacial or limb defects on gross observations of the fetuses. In serial longitudinal sections, no pathological changes were evident in any of the tissues, including the kidneys and liver. Therefore, the pomegranate extracts appeared to be safe for the fetus.
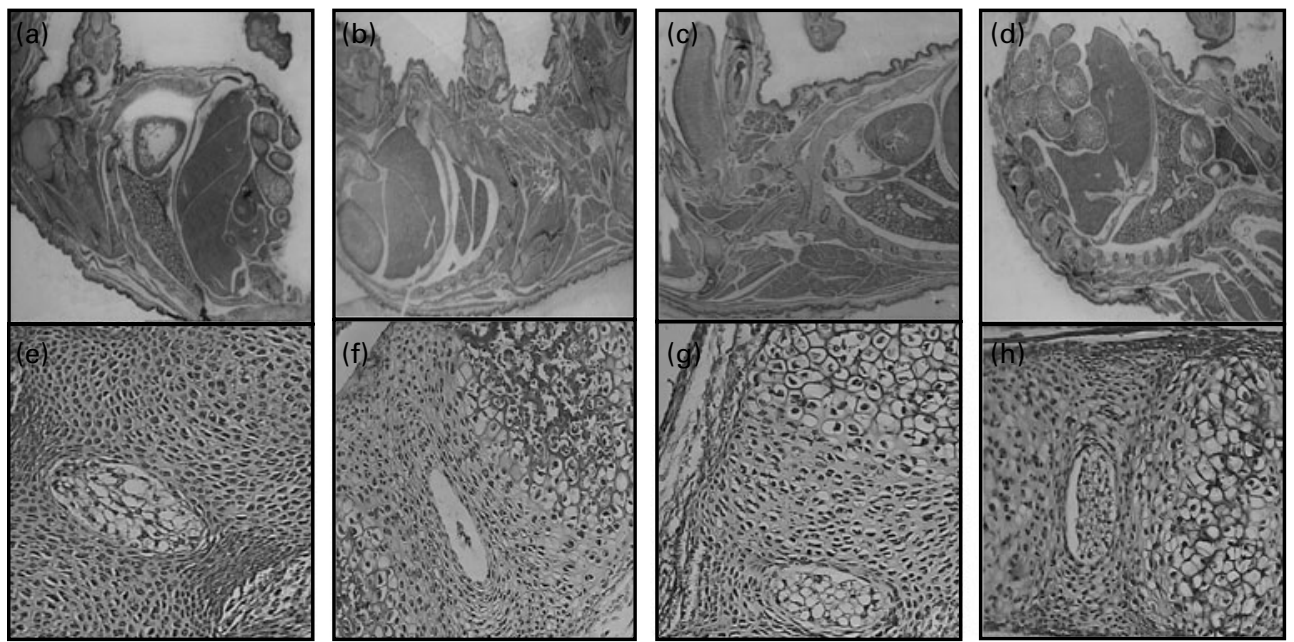

Fig. 3. Effects of pomegranate extracts on $(a-d)$ longitudinal sections of the trunk and $(e-h)$ vertebral column of mouse fetuses. (a, e) Control group, (b, f) pomegranate husk extract, $(\mathrm{c}, \mathrm{g})$ pomegranate husk and juice extract and $(\mathrm{d}, \mathrm{h})$ pomegranate juice extract. The experimental groups showed no pathological changes compared with the control group. Haematoxylin and eosin staining, (a-d) $40 \times$ and $(e-h) 100 \times$.
Dietary supplementation with the pomegranate extracts in pregnant mice increased femoral length and bone osteogenesis index in the fetuses. This index can be influenced by $\mathrm{Ca}$ content, and the $\mathrm{Ca}$ required for ossification in the developing fetus may come from the mother's blood and bone reserves. Feeding with PJE increased bone Ca content in pregnant mice. We therefore suggest that pomegranate extract may improve ossification in fetuses without side effects such as osteopoenia in their mothers. Other researchers have also shown positive effects of pomegranate extract on bone properties in the menopausal syndrome ${ }^{(11)}$ and in a model of osteoarthritis ${ }^{(12,20)}$. Coumoestrol, one of the phytooestrogenic components of pomegranate, was found to enhance neonatal and adult mice osteoblast proliferation ${ }^{(4)}$ Isoflavonoids, another phyto-oestrogen in pomegranates, increased BMD in fetuses ${ }^{(10)}$. These phyto-oestrogens have been reported to pass through the placenta and reach the embryonic circulation ${ }^{(21)}$. The present in vitro data showed that the extracts may have indeed influenced bone matrix 

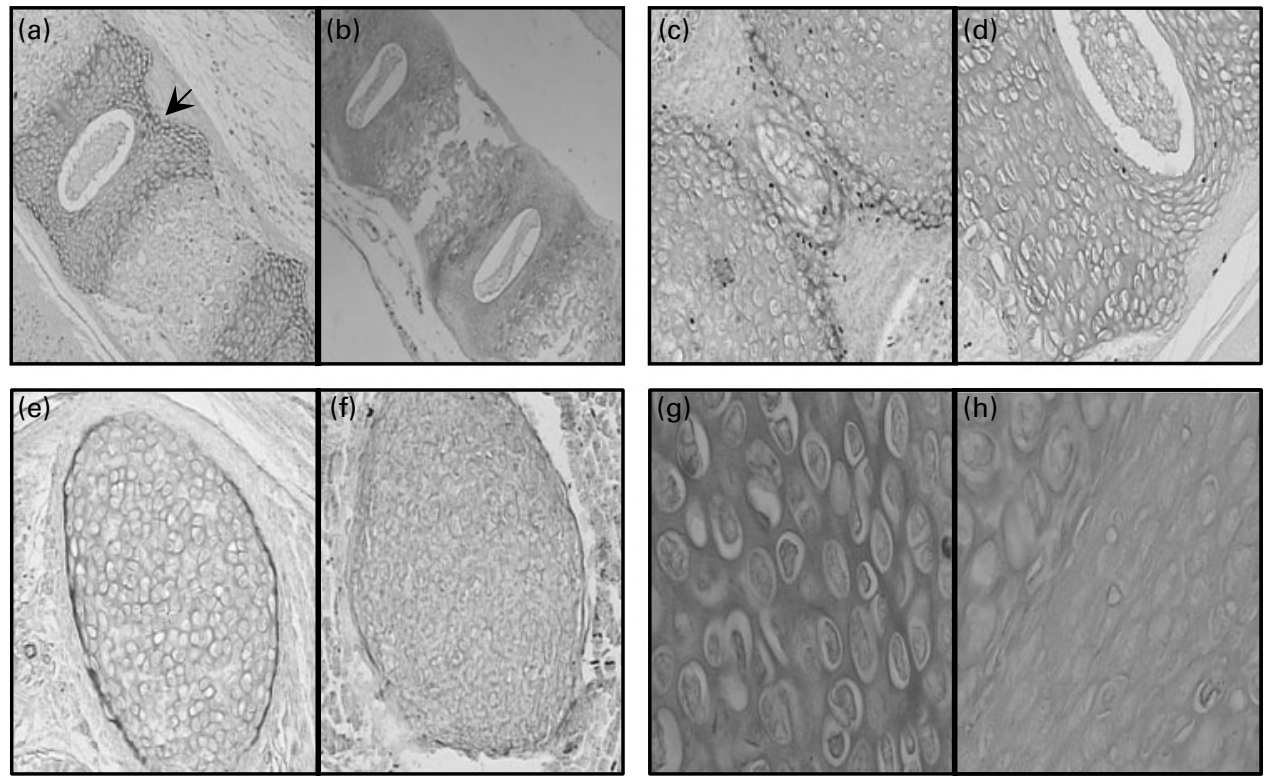

Fig. 4. Mouse embryos on day 18 of gestation stained with lectins. The perichondrium $(\rightarrow)$ in the vertebral cartilage of mice treated with pomegranate husk extract reacted more intensely with (a) Bandeiraea simplicifolia agglutinin (BSAI-B4) than in the (b) control group $(40 \times$ ). In pomegranate juice extract-treated mice, the vertebral and intervertebral disc cartilage stained more intensely with (c) BSAI-B4 and (d) Ulex europeaeus agglutinin (UEA; $100 \times$ ). The perichondrium of costal cartilages was stained more intensely with (e) BSAl-B4 in pomegranate husk extract-treated mice compared with (f) control mice (100 $\times$ ). In control mice, costal cartilages were stained more intensely with $(g)$ concanavalin $A$ and $(h)$ UEA $(400 \times)$.

precipitation. This effect may be attributable to the flavonoids in the extracts.

Another main component of pomegranate juice and seed oil is ellagic $\operatorname{acid}^{(2)}$. A recent study ${ }^{(22)}$ has demonstrated that ellagic acid has osteoblastic activity and influences osteoblastic differentiation and bone extracellular matrix formation in vitro. In this connection, it was found that phyto-oestrogens were transferred from the mother to the fetus. Therefore, pomegranate extracts can favour BMD and increase the osteogenesis index without causing congenital disorders. Other studies $^{(23,24)}$ have reported that the phyto-oestrogen genistein is also non-toxic for fetuses. Our observations confirmed that feeding with the extracts led to no histopathological changes or toxic effects in the fetus ${ }^{(25)}$.
We found that galactose-containing components were strongly expressed in the vertebral cartilage. Glycoconjugates play important roles in cell differentiation and developmental processes. We showed that the uptake of BSAI-B4 was significantly higher in fetuses from PJE- and PHE-treated mice compared with those from the control group. In this connection, an isoform of this lectin was shown to selectively visualise prechondral aggregations ${ }^{(26)}$. The present findings thus suggest that the differences between groups in the expression of BSAI-B4-containing glycoconjugates may be related to a positive effect of the extract on the differentiation potential of mesenchymal cells towards chondrogenesis and osteogenesis.

Our viability tests showed higher numbers of viable cells in cultures exposed to the extract than in control cultures,

Table 3. Effect of pomegranate extracts on light absorbency of viable cells, diameter and number of nodules in 9 and $14 \mathrm{~d}$ cultures (Mean values and standard deviations)

\begin{tabular}{|c|c|c|c|c|c|c|c|c|c|c|c|c|c|}
\hline \multirow[b]{3}{*}{ Groups } & \multirow{3}{*}{$\begin{array}{c}\text { Extract } \\
\text { concentration } \\
(\mu \mathrm{g} / \mathrm{ml})\end{array}$} & \multicolumn{4}{|c|}{ Light absorbency (OD) } & \multicolumn{4}{|c|}{ Nodule diameter (mm) } & \multicolumn{4}{|c|}{ Number of nodules } \\
\hline & & \multicolumn{2}{|c|}{$9 \mathrm{~d}$ culture } & \multicolumn{2}{|c|}{$14 \mathrm{~d}$ culture } & \multicolumn{2}{|c|}{$9 \mathrm{~d}$ culture } & \multicolumn{2}{|c|}{$14 \mathrm{~d}$ culture } & \multicolumn{2}{|c|}{$9 \mathrm{~d}$ culture } & \multicolumn{2}{|c|}{$14 \mathrm{~d}$ culture } \\
\hline & & Mean & SD & Mean & SD & Mean & SD & Mean & SD & Mean & SD & Mean & SD \\
\hline CON & 0 & 0.10 & 0.02 & 0.22 & 0.02 & 0.05 & 0.02 & 0.12 & 0.11 & 118.33 & 32.87 & 39.67 & 8.96 \\
\hline \multirow[t]{3}{*}{ PHE } & 10 & $0.11^{a}$ & 0.00 & 0.23 & 0.04 & $0.04^{e}$ & 0.02 & $0.09^{*}$ & 0.08 & $82.00^{\mathrm{k}}$ & 21.28 & $94.66^{* 0}$ & $8 \cdot 14$ \\
\hline & 100 & $0.63^{\star a, b}$ & 0.45 & 0.22 & 0.03 & 0.05 & 0.03 & $0.08^{*}$ & 0.05 & $91.33^{\prime}$ & $12 \cdot 50$ & $98 \cdot 00^{* \mathrm{P}}$ & 9.85 \\
\hline & 1000 & $0.11^{\mathrm{b}}$ & 0.01 & 0.21 & 0.02 & $0.06^{\star e}$ & 0.03 & $0.08^{\star}$ & 0.03 & $54 \cdot 00^{\star k, l}$ & 19.92 & $34.00^{o, p}$ & 11.53 \\
\hline \multirow[t]{3}{*}{ PME } & 10 & 0.14 & 0.02 & $0.20^{\star c}$ & 0.02 & $0.07^{\star}$ & 0.03 & $0.08^{\star h}$ & 0.06 & $118 \cdot 33^{\mathrm{m}}$ & $27 \cdot 43$ & $100 \cdot 00^{* q}$ & 10.82 \\
\hline & 100 & 0.14 & 0.03 & $0.17^{\star}$ & 0.01 & 0.06 & 0.02 & $0.08^{\star i}$ & 0.06 & $126 \cdot 33^{n}$ & $10 \cdot 26$ & $79 \cdot 33^{\star r}$ & 18.01 \\
\hline & 1000 & 0.14 & 0.02 & $0.16^{c}$ & 0.01 & 0.06 & 0.04 & $0 \cdot 12^{\mathrm{h}, \mathrm{i}}$ & 0.11 & $115 \cdot 67^{\mathrm{m}, \mathrm{n}}$ & 21.78 & $30.67^{q, r}$ & 11.59 \\
\hline \multirow[t]{3}{*}{ PJE } & 10 & $0 \cdot 12$ & 0.00 & $0 \cdot 16^{\star d}$ & 0.01 & $0.05^{f}$ & 0.03 & $0.07^{\star j}$ & 0.06 & $115 \cdot 00$ & $25 \cdot 24$ & $77 \cdot 00^{*}$ & 8.66 \\
\hline & 100 & 0.14 & 0.01 & $0.15^{\star}$ & 0.01 & $0.06^{\star 9}$ & 0.03 & $0 \cdot 10^{j}$ & 0.10 & $98 \cdot 33$ & 21.08 & 53.00 & $15 \cdot 39$ \\
\hline & 1000 & 0.14 & 0.02 & $0 \cdot 13^{\star d}$ & 0.01 & $0.09^{\star f, g}$ & 0.06 & $0.08^{\star}$ & 0.07 & $127 \cdot 33$ & $27 \cdot 15$ & 44.00 & $10 \cdot 15$ \\
\hline
\end{tabular}

OD, optical density; CON, control; PJE, pomegranate juice extract; PHE, pomegranate husk extract; PME, mixture of pomegranate husk and juice extract.

${ }^{a-r}$ Mean values with unlike superscript letters were significantly different $(P<0.05)$.

${ }^{*}$ Mean values were significantly different from those of the control group $(P<0.05)$. 

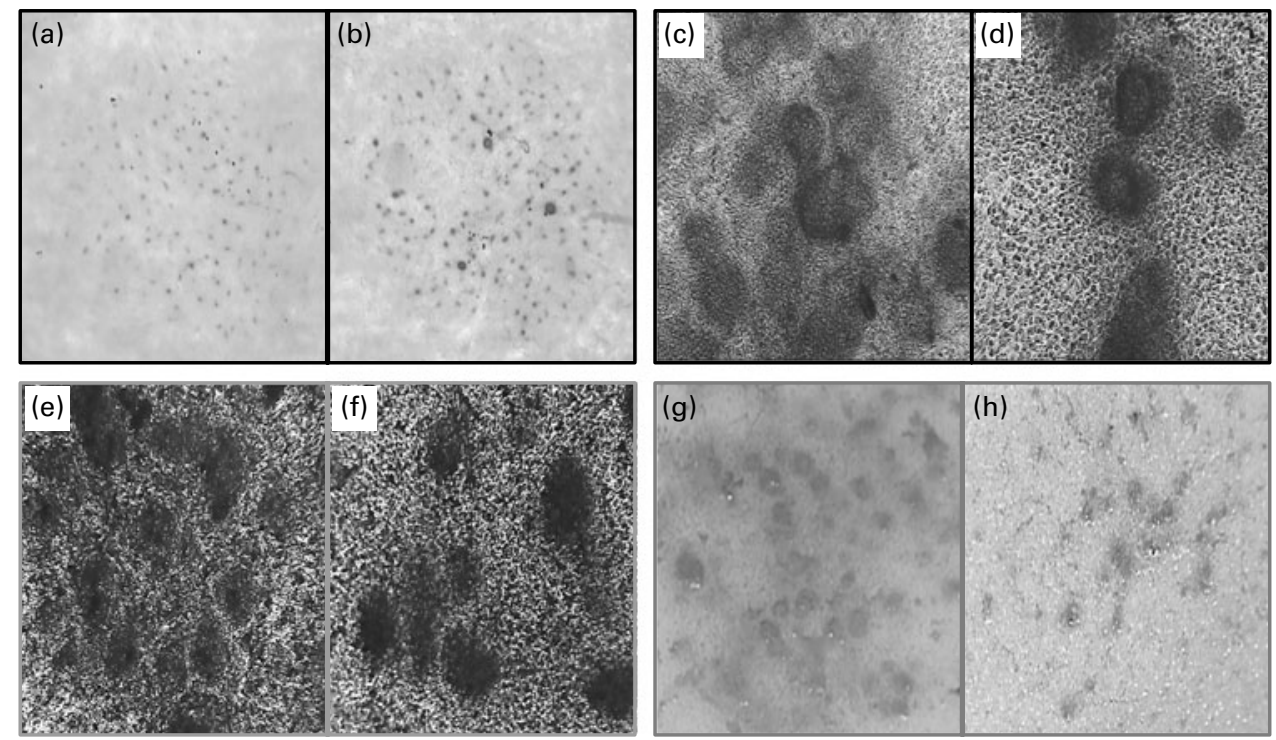

Fig. 5. Mesenchymal cells exposed to different pomegranate extracts and stained with (a, b) alcian blue, (c, d) alizarin red S or (e-h) Von Kossa stain. On day 9 , cells exposed to (b) $1000 \mu \mathrm{g} / \mathrm{ml}$ pomegranate husk and juice extract had more cartilage nodules with larger diameters than (a) control cell cultures (15 $\times$ ). On day 14 , cells exposed to (d) $10 \mu \mathrm{g} / \mathrm{ml}$ pomegranate husk extract and stained with alizarin red $\mathrm{S}$ had fewer nodules with less Ca content compared with (c) control cultures $(100 \times)$. On day 14 , cells exposed to (f) $10 \mu \mathrm{g} / \mathrm{ml}$ pomegranate husk and juice extract and stained with Von Kossa stain had fewer nodules with smalle diameters compared with $(\mathrm{e})$ control cultures $(100 \times)$. On the same day, cells exposed to $(\mathrm{h}) 10 \mu \mathrm{g} / \mathrm{ml}$ pomegranate husk extract and stained with silver nitrate had fewer nodules with smaller diameters compared with $(\mathrm{g})$ control cultures $(40 \times)$.

especially on day 14. The extract-treated cells formed larger chondrifying nodules after $9 \mathrm{~d}$, and thereafter the size of the nodules decreased, as shown by measurements made on day 14, while nodular counts showed the opposite trend. In general, extract-treated cultures showed higher viability, larger nodular diameters and more nodules than control cultures. These differences may be attributable to higher rates of cell division and differentiation, as well as a higher rate of matrix formation. Our observations are further evidence that the content of the extract induced chondrogenesis and osteogenesis.

In this connection, the phyto-oestrogen genistein has been previously found to stimulate bone mineralisation in vitro ${ }^{(27,28)}$. In addition, Feijoa sellowiana leaf extract (rich in ellagic acid) significantly increased mineralisation in two human osteoblast cell lines in vitro ${ }^{(29)}$. Coumoestrol has been shown to inhibit bone resorption in rat limb buds in vitro ${ }^{(30)}$. Daidzein and genistein have been reported to have stimulatory effects on protein synthesis and alkaline phosphatase release by osteoblasts in vitro ${ }^{(31,32)}$. The mechanisms through which genistein and daidzein suppressed osteoclast activity have been debated in several studies, and include the induction of apoptosis, activation of protein tyrosine phosphatase, inhibition of cytokines, changes in intracellular $\mathrm{Ca}^{2+}$ and membrane depolarisation ${ }^{(33-36)}$. The evidence from this earlier work is consistent with the present finding that on day 14 , cell viability and nodular number were reduced in mesenchymal limb bud cultures from mouse embryos. This result may be attributable to increased mineralisation and bone matrix formation. In turn, higher mineral precipitation and matrix formation may have induced a higher rate of cell death. The variations we saw in the degree of the effects of the different pomegranate extracts may be related to different constituents in the extracts.

In summary, we conclude that although pomegranate extracts can reduce CRL and body weight in mouse fetuses, they also promote the differentiation of mesenchymal cells into cartilage and bone both in vivo and in vitro.

\section{Acknowledgements}

The present study was financially supported by the Vice-Chancellory for Research of Shiraz University. The authors thank Mrs Arasteh for extract preparation. We thank K. Shashok (AuthorAID in the Eastern Mediterranean) for improving the use of English in the manuscript and M. Gholami at the Center for Development of Clinical Research of Nemazee Hospital for research assistance. The present study was done in fulfilment of the requirements for the MS degree defended by F. P. T. T.-K. conducted the in vitro study and M. M. conducted the in vivo experiments. The authors declare that there is no conflict of interest.

\section{References}

1. Bown D (1995) Encyclopaedia of Herbs and Their Uses. London: Dorling Kindersley.

2. Jurenka J (2008) Therapeutic applications of pomegranate (Punica granatum L.): a review. Alterm Med Rev 13, $128-144$.

3. Moneam NMA, Sharasky AS \& Badreldin MM (1988) Oestrogen content of pomegranate seeds. J Chromatogr $\mathbf{4 3 8}$, 438-442.

4. Sun JS, Li YY, Liu M, et al. (2007) Effects of coumestrol on neonatal and adult mice osteoblasts activities. J Biomed Mater Res A 81, 214-223. 
5. Kuiper GG, Lemmen JG, Carlsson B, et al. (1998) Interaction of estrogenic chemicals and phytoestrogens with estrogen receptor beta. Endocrinology 139, 4252-4263.

6. Arts J, Kuiper GG, Janssen JM, et al. (1997) Differential expression of estrogen receptors $\alpha$ and $\beta$ mRNA during differentiation of human osteoblast SV-HFO cells. Endocrinology 138, 5067-5070.

7. Onoe Y, Miyaura C, Ohta H, et al. (1997) Expression of estrogen receptor $\beta$ in rat bone. Endocrinology 138, 4509-4512.

8. Morito K, Hirose T, Kinjo J, et al. (2001) Interaction of phytoestrogens with estrogen receptors alpha and beta. Biol Pharm Bull 24, 351-356.

9. Setchell KD \& Lydeking-Olsen E (2003) Dietary phytoestrogens and their effect on bone: evidence from in vitro and in vivo, human observational, and dietary intervention studies. Am J Clin Nutr 78, 593-609.

10. Mardon J, Mathey J, Kati-Coulibaly S, et al. (2008) Influence of lifelong soy isoflavones consumption on bone mass in the rat. Exp Biol Med 233, 229-237.

11. Mori-Okamoto J, Otawara-Hamamoto $\mathrm{Y}$, Yamato $\mathrm{H}$, et al. (2004) Pomegranate extract improves a depressive state and bone properties in menopausal syndrome model ovariectomized mice. J Ethnopharmacol 92, 93-101.

12. Hadipour-Jahromy M \& Mozaffari-Kermani R (2010) Chondroprotective effects of pomegranate juice on monoiodoacetate-induced osteoarthritis of the knee joint of mice. Phytother Res 24, 182-185.

13. Bancroft JD \& Stevens A (1991) Theory and Practical of Histology Techniques. New York: Churchill Livingstone.

14. Kulyk MW \& Hoffman LM (1996) Ethanol exposure stimulates cartilage differentiation by embryonic limb mesenchyme cells. Exp Cell Res 223, 290-300.

15. Esmaillzadeh A, Tahbaz F, Gaieni I, et al. (2006) Cholesterollowering effect of concentrated pomegranate juice consumption in type II diabetic patients with hyperlipidemia. Int J Vitam Nur Res 76, 147-151.

16. Das AK, Mandal SC, Banerjee SK, et al. (2001) Studies on the hypoglycemic activity of Punica granatum seed in streptozotocin induced diabetic rats. Phytother Res 15, 628-629.

17. Koba K, Imamura J, Akashoshi A, et al. (2007) Genetically modified rapeseed oil containing cis-9, trans-11, cis-13-octadecatrienoic acid affects body fat mass and lipid metabolism in mice. J Agric Food Chem 55, 3741-3748.

18. Yang DJ, Chang YY, Hsu CL, et al. (2010) Antiobesity and hypolipidemic effects of polyphenol-rich longan (Dimocarpus longans Lour.) flower water extract in hypercaloric-dietary rats. J Agric Food Chem 58, 2020-2027.

19. Dolinoy DC, Weidman JR, Waterland RA, et al. (2006) Maternal genistein alters coat color and protects Avy mouse offspring from obesity by modifying the fetal epigenome. Environ Health Perspect 114, 567-572.

20. Shukla M, Gupta K, Rasheed Z, et al. (2008) Consumption of hydrolysable tannins-rich pomegranate extract suppresses inflammation and joint damage in rheumatoid arthritis. Nutrition 24, 733-739.
21. Degen GH, Janning P, Diel P, et al. (2002) Transplacental transfer of the phytoestrogen daidzein in DA/Han rats. Arch Toxicol 76, 23-29.

22. Papoutsi Z, Kassi E, Chinou I, et al. (2007) Walnut extract (Juglans regia L.) and its component ellagic acid exhibit anti-inflammatory activity in human aorta endothelial cells and osteoblastic activity in the cell line KS483. Br J Nutr 99, 715-722.

23. Tousen Y, Umeki M, Nakashima Y, et al. (2006) Effects of genistein, an isoflavone, on pregnancy outcome and organ weights of pregnant and lactating rats and development of their suckling pups. J Nutr Sci Vitaminol 52, 174-182.

24. Mcclain RM, Wolz E, Davidovich A, et al. (2007) Reproductive safety studies with genistein in rats. Food Chem Toxicol 45, 1319-1332

25. Patel C, Dadhaniya P, Hingorani L, et al. (2008) Safety assessment of pomegranate fruit extract: acute and subchronic toxicity studies. Food Chem Toxicol 46, 2728-2735.

26. Zschäbitz A, Krahn V, Schmidt W, et al. (1999) Expression patterns of complex glycoconjugates and endogenous lectins during fetal development of the viscerocranium. Ann Anat 181, 117-121.

27. Pan W, Quarles LD, Song LH, et al. (2005) Genistein stimulates the osteoblastic differentiation via NO/CGMP in bone marrow culture. J Cell Biochem 94, 307-316.

28. Morris C, Thorpe J, Ambrosio L, et al. (2006) The soybean isoflavone genistein induces differentiation of MG63 human osteosarcoma osteoblasts. J Nutr 136, 1166-1170.

29. Ayoub NA, Hussein SA, Hashim AN, et al. (2009) Bone mineralization enhancing activity of a methoxyellagic acid glucoside from a Feijoa sellowiana leaf extract. Pharmazie 64, 137-141.

30. Tsutsumi N (1995) Effect of coumestrol on bone metabolism in organ culture. Biol Pharm Bull 18, 1012-1015.

31. Sugimoto E \& Yamaguchi M (2000) Anabolic effect of genistein in osteoblastic MC3T3-E1 cells. Int J Mol Med 5, $515-520$.

32. Sugimoto E \& Yamaguchi M (2000) Stimulatory effect of daidzein in osteoblastic MC3T3-E1 cells. Biochem Pharmacol 259, 471-475.

33. Blair HC, Jordan SE, Peterson TG, et al. (1996) Variable effects of tyrosine kinase inhibitors on avian osteoclastic activity and reduction of bone loss in ovariectomized rats. J Cell Biochem 61, 629-637.

34. Okamoto F, Okabe K \& Kajiya H (2001) Genistein, a soybean isoflavone, inhibits inward rectifier $\mathrm{K}^{+}$channels in rat osteoclasts. Jpn J Physiol 51, 501-509.

35. Gao YH \& Yamaguchi M (1999) Suppressive effects of genistein on rat bone osteoclasts: apoptosis is induced through $\mathrm{Ca}^{2+}$ signaling. Biol Pharm Bull 22, 805-809.

36. Gao YH \& Yamaguchi M (2000) Suppressive effect of genistein on rat bone osteoclasts: involvement of protein kinase inhibition and protein tyrosine phosphatase activation. Int J Mol Med 5, 261-267. 